The Egyptian Journal of Hospital Medicine (April 2019) Vol. 75 (1), Page 1946-1952

\title{
A Comparison between Volume-Controlled Ventilation and Pressure-Controlled Ventilation in Providing Better Oxygenation in Obese Patients Undergoing Laparoscopic Cholecystectomy \\ Said Ahmed Ali, Said Mohamed Fayad, Nasr Abd Alaziz Mohamed Saad and Mohammad Abd AlHady Abd Allatif \\ Department of Anesthesia and Intensive Care, Faculty of Medicine - Al-Azhar University Corresponding author: Mohammad Abd AlHady Abd Allatif, Mobile: (+20)01063355972, \\ E-Mail: meinemeinung_schonheiten@yahoo.com
}

\begin{abstract}
Background: The main goal of mechanical ventilation is the maintenance of adequate oxygenation and ventilation. There is no guidelines on the mechanical ventilation in obese patients. This study aims to compare the effect of pressure controlled ventilation PCV vs. volume controlled ventilation VCV on oxygenation parameters in obese patients undergoing laparoscopic cholecystectomy.

Methods: 70 obese patient of ASA physical status II, Body Mass Index of 30-40 kg/m2, scheduled for laparoscopic cholecystectomy were included in this prospective randomized study. All patients received VCV. Fifteen minutes after creation of pneumoperitoneum, they were randomized to receive either VCV (Group V) or PCV (Group P). The ventilatory parameters were adjusted accordingly to maintain the end- tidal $\mathrm{CO}_{2}$ between 30 and $40 \mathrm{mmHg}$.

Primary outcome variable was mean airway pressures. Secondary outcomes were $\mathrm{PO}_{2} / \mathrm{FiO}_{2}$ ratio, dead space to tidal volume ratio and alveolar arterial oxygen tension gradient before and after creation of pneumoperitoneum. Results: Patients in group $\mathrm{P}$ showed a statistically significant $(P<0.05)$ higher level of $\mathrm{PaO}_{2} / \mathrm{FiO}_{2}$ ratio and mean airway pressure and lower value of $\mathrm{PAO}_{2}-\mathrm{PaO}_{2}$, dead space to tidal volume ratio and peak airway pressure than those in group $\mathrm{V}$.
\end{abstract}

Conclusion: PCV is a more efficient mode of ventilation in comparison with VCV mode regarding oxygenation in obese patients undergoing laparoscopic cholecystectomy.

Keywords: Volume-Controlled Ventilation, Pressure-Controlled Ventilation, Obese Patients Undergoing, Laparoscopic Cholecystectomy

\section{INTRODUCTION}

Obesity results in several pathophysiological changes of the respiratory system mechanics that promote the development of intraoperative atelectasis and exaggerate the impairment of gas exchange ${ }^{(1-3)}$.

As a consequence, arterial oxygenation is inversely related to body mass index (BMI) ${ }^{(4)}$

Obesity also, is a well- established risk factor for cholelithiasis for which laparoscopic cholecystectomy is the routinely performed surgery ${ }^{(2)}$. The cardiopulmonary and metabolic changes during pneumoperitoneum are complex and related to the level of intraabdominal pressure, duration of pneumoperitoneum, patient position and the ventilation mode ${ }^{(5,6)}$.

Several studies have been performed to determine the optimal ventilatory settings in obese patients ${ }^{(6)}$.

The primary goal of mechanical ventilation is the maintenance of adequate gas exchange, which must be achieved with minimum lung injury and the lowest possible degree of hemodynamic impairment $^{(7)}$.

The most frequently used ventilation mode in general anesthesia is volume-controlled ventilation (VCV) as this has been the only available mode on ventilators for a long time ${ }^{(8)}$.
This mode uses a constant flow to deliver tidal volume but can result in higher airway pressures especially during laparoscopic procedures due to decreased lung and chest wall compliance and reduced functional residual capacity which impairs alveolar ventilation and leads to ventilator induced lung injury ${ }^{(9)}$.

Pressure-controlled ventilation (PCV) has been proposed as an alternative to VCV in ICU patients with adult respiratory distress syndrome, and in obese patients to achieve adequate oxygenation and normocapnia with minimum lung injury and hemodynamic impairment ${ }^{(\mathbf{1 0})}$.

PCV uses a decelerating flow, which reaches the highest possible value at the beginning of inspiration. Flow diminishes throughout inspiration according to the pressure target, and the resulting tidal volume $\left(\mathrm{V}_{\mathrm{t}}\right)$ depends on the pressure limitation and on the chest compliance ${ }^{(9)}$.

Although PCV potentially provides greater control over airway pressure by virtue of its decelerating inspiratory flow pattern, it remains a relatively less frequently used ventilation strategy in the operating theatre. Furthermore, PCV may be associated with increased mean airway pressure that in turn may improve oxygenation ${ }^{(\mathbf{1 1 )}}$. 
There is no special guideline for the best ventilation mode during laparoscopic anesthesia in obese patients and there are too many studies with different controversial points ${ }^{(\mathbf{1 2}, \mathbf{1 3})}$.

We therefore decided to compare the effects of the two ventilation modes with respect to pulmonary mechanics and gas exchange in obese patients undergoing laparoscopic cholecystectomy, in a randomized controlled trial.

The aim of this randomized controlled study is to compare the effect of pressure-controlled ventilation vs. volume-controlled ventilation modes on mean airway pressure, peak airway pressure, $\mathrm{PO}_{2} / \mathrm{FIO}_{2}$ ratio, respiratory rate, tidal volume, alveolar-arterial oxygen tension gradient, dead space ventilation to tidal volume ratio, and hemodynamic variables (heart rate and mean arterial blood pressure) in patients undergoing laparoscopic cholecystectomy.

We chose to test the null hypothesis that ventilation mode has no effect on mean airway pressure; this was chosen as the primary outcome measure as it not only reflects the average of airway pressure over the entire respiratory cycle but is also directly related to gas distribution and exchange in alveoli with non-homogeneous time constants.

\section{PATIENTS AND METHODS}

After approval of Department of Anaesthesia, Faculty of Medicine Al-Azhar University and the Medical Ethics Committee, an informed consent was obtained from all patients.

This, randomized control study was conducted on 70 obese adult patients of ASA physical status II, admitted to Al-Hussien Hospital and Al SayedGalal Hospital, scheduled for elective laparoscopic cholecystectomy.

\section{Inclusion Criteria:}

1- Male and female patients aging from 20 years to 60 years old.

\section{2- BMI $30-40 \mathrm{~kg} / \mathrm{m}^{2}$}

3- ASA II physical status patients scheduled for elective laparoscopic cholecystectomy.

\section{Exclusion criteria:}

- Patient refusal.

- Inability to maintain an appropriate $\mathrm{EtCO}_{2}$

- Inability to remove the endotracheal tube in the operating room

- Conversion to laparotomy

- Major obstructive or restrictive pulmonary disease (defined as less than $70 \%$ of predicted values for pulmonary function test).

We calculated the required sample size at a power of $80 \%$ and $\alpha$ of 0.05 to be 16 patients in each group, based on previously published data that demonstrated mean (SD) of mean airway pressure of 7 (2) and 9 (2) $\mathrm{cmH}_{2} \mathrm{O}$ with $\mathrm{VC}$ and $\mathrm{PC}$ ventilation, respectively. We included 35 patients in each group for possible drop-outs.

Routine preoperative assessment was done to all patients including: history, clinical examination, laboratory investigations as (complete blood picture, liver function tests, kidney function tests, prothrombin time and partial thromboplastin time), electrocardiogram (and echocardiography if ordered by the cardiologist), and pulmonary function tests. Other investigations were done according to the medical condition.

A peripheral venous access and an arterial access were secured and a baseline arterial blood sample was drawn for arterial blood gas (ABG) analysis.

All patients were monitored with 5 lead ECG to monitor heart rate and rhythm, pulse oximetry to monitor oxygen saturation, non-invasive blood pressure monitoring with a large cuff, suitable for obese patients and capnography to detect $\mathrm{EtCO}_{2}$ (using BSM-3562 Nihon Kohden, Nihon Kohden Corporation, Tokyo Japan).

A standard protocol for general anesthesia with endotracheal intubation and controlled ventilation was conducted in all patients, where all patients received intravenous injection of ranitidine $50 \mathrm{mg}$ and metoclopramide $10 \mathrm{mg}$ preoperatively, and an injection of fentanyl $2 \mathrm{mcg} / \mathrm{kg}$ (TBW) two minutes before induction.

After proper pre-oxygenation, anesthesia was induced with injection of propofol $2 \mathrm{mg} / \mathrm{kg}$ (TBW). The trachea was intubated with a cuffed endotracheal tube of appropriate size after achieving adequate relaxation with injection of rocuronium $0.6-1.2 \mathrm{mg} / \mathrm{kg}$ (IBW).

The lungs were ventilated with $100 \%$ oxygen and isoflurane 1- 1.2\% (using Dräger Fabius Plus anesthesia machine, Dräger Company, Jermany). Muscle relaxation was maintained with injection of rocuronium $0.1-0.2 \mathrm{mg} / \mathrm{kg}$ (IBW) every 45 minutes to maintain muscle relaxation.

The anaesthetist administered further drugs and fluids as clinically indicated, while maintaining the patient's heart rate and blood pressure within $20 \%$ of baseline.

To start with, all patients' lungs were ventilated using VCV with a tidal volume of $8 \mathrm{~mL} / \mathrm{kg}$ and inspiratory/expiratory ratio of $1: 2$. Respiratory rate was adjusted to obtain an $\mathrm{EtCO}_{2}$ of $30-40 \mathrm{mmHg}$.

After pneumoperitoneum (intraabdominal pressure $10-12 \mathrm{mmHg}$ ), patients were placed in a $25^{\circ}$ head-up position. Patients were randomized with the help of a computer-generated random number list to receive either VCV (Group V; $\mathrm{n}=35$ ) or PCV (Group P; $n=35$ ). The ventilatory settings in both groups were chosen based on a specifically derived algorithm. 


\section{In Group V:}

Ventilation was continued with a tidal volume of $8 \mathrm{~mL} / \mathrm{kg}$ (IBW). The initial tidal volume was increased by $1 \mathrm{~mL} / \mathrm{kg}$ every $5 \mathrm{~min}$ until $12 \mathrm{~mL} / \mathrm{kg}$, and the respiratory rate was increased by $2 / \mathrm{min}$ every 5 min till 20/min to maintain $\mathrm{EtCO}_{2}$ between 30 and $40 \mathrm{mmHg}$.

Following fall in $\mathrm{EtCO}_{2}<30 \mathrm{mmHg}$, the respiratory rate was decreased by $2 /$ min every $5 \mathrm{~min}$ till $8 / \mathrm{min}$, with a decrease in tidal volume of 1 $\mathrm{mL} / \mathrm{kg}$ until $6 \mathrm{~mL} / \mathrm{kg}$.

Patients in VCV requiring tidal volume $>12$ $\mathrm{mL} / \mathrm{kg}$ or respiratory rate $>20 / \mathrm{min}$ to maintain normocarbia were dropped from the study.

\section{In Group P:}

The airway pressure not exceeding 30 $\mathrm{cmH}_{2} \mathrm{O}$ was set to provide a tidal volume of $8 \mathrm{~mL} / \mathrm{kg}$ (IBW). Respiratory rate was adjusted to keep an $\mathrm{EtCO}_{2}$ of $30-40 \mathrm{mmHg}$. Following an increase in $\mathrm{EtCO}_{2}$, the airway pressure increased by $2 \mathrm{cmH}_{2} \mathrm{O}$ every 5 min until $30 \mathrm{cmH}_{2} \mathrm{O}$ and the respiratory rate was increased by $2 / \mathrm{min}$ every $5 \mathrm{~min}$ till $20 / \mathrm{min}$, achieving the target $\mathrm{EtCO}_{2}$. Following a fall in $\mathrm{EtCO}_{2}<30 \mathrm{mmHg}$, the respiratory rate was decreased by $2 / \mathrm{min}$ every $5 \mathrm{~min}$ till $8 / \mathrm{min}$, with a decrease in airway pressure by $2 \mathrm{cmH}_{2} \mathrm{O}$ every 5 min until $10 \mathrm{cmH}_{2} \mathrm{O}$.

Patients in PCV requiring airway pressure $>30$ $\mathrm{cmH}_{2} \mathrm{O}$ and respiratory rate $>20 / \mathrm{min}$ to maintain normocarbia were dropped from the study.

After completion of surgery, neostigmine 0.05 $\mathrm{mg} / \mathrm{kg}$ and atropine $0.02 \mathrm{mg} / \mathrm{kg}$ were administered. Patients were transferred to the recovery room after extubation of the trachea and oxygen by facemask was provided $\left(\mathrm{FIO}_{2} 0.4\right)$; any episodes of $\mathrm{SpO} 2<$ $95 \%$ in the first $2 \mathrm{~h}$ were noted.
Hemodynamic data (heart rate, and mean arterial blood pressure), and ventilatory data (respiratory rate, tidal volume, and mean airway pressure) were recorded just before insufflation as baseline reading, during dissection of the cystic pedicle, after clamping of cystic pedicle, and before desufflation and the mean of the last three records were calculated for each patient and used for statistical analysis.

The ratio of arterial oxygen partial pressure to fractional inspired oxygen $\left(\mathrm{PaO}_{2} / \mathrm{FiO}_{2}\right.$ ratio), alveolar-arterial oxygen tension gradient $\left(\mathrm{A}-\mathrm{a} \mathrm{O}_{2}\right.$ Gradient $=\left[\left(\mathrm{FiO}_{2}\right) \times\left(\right.\right.$ Atmospheric Pressure $-\mathrm{H}_{2} \mathrm{O}$ Pressure $)$ - $\left.\left.\left(\mathrm{PaCO}_{2} / 0.8\right)\right]-\mathrm{PaO}_{2}\right)$ and dead space ventilation to tidal volume ratio $\left(\frac{v_{D}}{v_{T}}=\frac{P_{a} C_{2}-P_{E C O_{2}}}{P_{a} C_{2}}\right)$ were calculated just before insufflation, during dissection of the cystic pedicle, after clamping of cystic pedicle, and before desufflation using baseline data and the mean of post insufflation data for each patient were calculated and used for statistical analysis.

\section{Statistical analysis}

All data collected were analysed using SPSS version 23(IBM, Somers, NY, USA). Data were presented as mean \pm standard deviation (SD) and no (\%). Chi-square test $\left(\mathrm{X}^{2}\right)$ was used as appropriate for comparison of non-parametric data. Unpaired Student $\mathrm{t}$-test $(\mathrm{t})$ was used to compare between the two groups in quantitative data. Probability $(\mathrm{P}$ value): $\mathrm{P}<0.05$ was considered significant.

\section{RESULTS}

Patients' characteristics as regard sex, age, and BMI showed no statistically significant differences between the two groups as shown in table (1).

\section{Data collection}

Table 1: Patients characteristics

\begin{tabular}{|c|c|c|c|}
\hline & $\begin{array}{l}\text { Group V } \\
(n=35)\end{array}$ & $\begin{array}{l}\text { Group P } \\
(n=35)\end{array}$ & P-value \\
\hline \multicolumn{4}{|l|}{ Sex } \\
\hline Female & $27(77.1 \%)$ & $31(88.6 \%)$ & \multirow[t]{2}{*}{$>0.05$} \\
\hline Male & $8(22.9 \%)$ & $4(11.4 \%)$ & \\
\hline \multicolumn{4}{|l|}{ Age (year) } \\
\hline Mean \pm SD & $37.86 \pm 9.7$ & $37.80 \pm 9.0$ & $>0.05$ \\
\hline \multicolumn{4}{|c|}{ BMI $\left(\mathrm{kg} / \mathrm{m}^{2}\right)$} \\
\hline Mean \pm SD & $34.49 \pm 2.5$ & $35.01 \pm 2.9$ & $>0.05$ \\
\hline
\end{tabular}

Values are presented as mean \pm SD or number (\%) 
A Comparison between Volume-Controlled Ventilation...

Regarding heart rate, mean arterial blood pressure, tidal volume and respiratory rate; the results showed no statistically significant difference between both groups at baseline ( $5 \mathrm{~min}$ after intubation), and after pneumoperitoneum as shown in table (2).

Table 2: Heart rate, mean arterial blood pressure, respiratory rate and tidal volume between both groups.

\begin{tabular}{|c|c|c|c|}
\hline & Group V & Group P & $\mathrm{P}$ value \\
\hline $\begin{array}{l}\text { HR Baseline (5 min after } \\
\text { intubation) }\end{array}$ & $86.29 \pm 6.7$ & $85.26 \pm 5.9$ & $>0.05$ \\
\hline $\begin{array}{cc}\text { HR } & \text { After } \\
\text { pneumoperitoneum }\end{array}$ & $87.80 \pm 5.2$ & $87.14 \pm 5.2$ & $>0.05$ \\
\hline $\begin{array}{l}\text { Mean arterial blood } \\
\text { pressure Baseline ( } 5 \mathrm{~min} \\
\text { after intubation) }\end{array}$ & $94.26 \pm 10.3$ & $93.99 \pm 8.8$ & $>0.05$ \\
\hline \begin{tabular}{ll}
\multicolumn{1}{c}{ Mean arterial } & blood \\
pressure & After \\
pneumoperitoneum &
\end{tabular} & $90.03 \pm 9.3$ & $89.79 \pm 8.5$ & $>0.05$ \\
\hline $\begin{array}{l}\text { Vt Baseline (5 min after } \\
\text { intubation) }\end{array}$ & $527.56 \pm 37.989$ & $541.99 \pm 45.831$ & $>0.05$ \\
\hline $\begin{array}{cc}\mathrm{Vt} & \text { After } \\
\text { pneumoperitoneum }\end{array}$ & $575.70 \pm 39.664$ & $566.21 \pm 41.727$ & $>0.05$ \\
\hline $\begin{array}{l}\text { RR Baseline (5 min after } \\
\text { intubation) }\end{array}$ & $12.14 \pm 0.648$ & $13.971 \pm 0.822$ & $<0.001 *$ \\
\hline $\begin{array}{cc}\text { RR } & \text { After } \\
\text { pneumoperitoneum }\end{array}$ & $12.20 \pm 0.677$ & $13.657 \pm 0.8023$ & $<0.001 *$ \\
\hline
\end{tabular}

Values are presented as mean \pm SD.

HR heart rate, Vt tidal volume, RR respiratory rate.

Regarding the peak inspiratory pressure, alveolar -arterial oxygen tension gradient and dead space ventilation to tidal volume ratio the results showed no statistically significant difference at baseline, but showed statistically but not clinically significant increase in group $\mathrm{V}$ compared to group $\mathrm{P}$ after pneumoperitoneum as shown in table (3).

Table 3: Peak inspiratory pressure, alveolar -arterial oxygen tension gradient and dead space ventilation to tidal volume ratio between both groups.

\begin{tabular}{|c|l|l|l|}
\hline & Group V & Group P & P value \\
\hline $\begin{array}{c}\text { PIP Baseline (5 min } \\
\text { after intubation) }\end{array}$ & $19.11 \pm 1.301$ & $19.26 \pm 1.669$ & $>0.05$ \\
\hline $\begin{array}{c}\mathrm{PIP} \text { After } \\
\text { pneumoperitoneum }\end{array}$ & $25.54 \pm 1.615$ & $24.20 \pm 1.431$ & $<0.001^{*}$ \\
\hline $\begin{array}{c}\mathrm{PAO}_{2}-\mathrm{PaO}_{2} \text { gradient } \\
\text { Baseline (5 min after } \\
\text { intubation) }\end{array}$ & $312.800 \pm 31.8053$ & $313.686 \pm 37.9766$ & $>0.05$ \\
\hline $\begin{array}{c}\mathrm{PAO} 2-\mathrm{PaO} \text { gradient } \\
\text { after pneumoperitoneum }\end{array}$ & $363.450 \pm 33.378$ & $339.857 \pm 34.398$ & $<0.005^{*}$ \\
\hline $\begin{array}{c}\text { Vd/Vt Baseline (5 } \\
\text { min after intubation) }\end{array}$ & $1784 \pm 0.03167$ & $1858 \pm 0.0315$ & $<0.001^{*}$ \\
\hline $\begin{array}{c}\mathrm{Vd} / \mathrm{Vt} \text { After } \\
\text { pneumoperitoneum }\end{array}$ & $1410 \pm 0.03012$ & $1254 \pm 0.02729$ & $<0.001^{*}$ \\
\hline
\end{tabular}

Values are presented as mean \pm SD.

* Statistically significant difference.

PIP peak inspiratory pressure $\mathrm{PAO}_{2}-\mathrm{PaO}_{2}$, Alveolar arterial oxygen tension gradient, $\mathrm{Vd} / \mathrm{Vt}$ dead space to tidal volume ratio. 
Regarding the mean airway pressure and the $\mathrm{PaO}_{2} / \mathrm{Fio}_{2}$ Ratio, the results showed no statistically significant difference at baseline, but showed statistically significant increase in $\mathrm{P}$ group in comparison to $\mathrm{V}$ group after pneumoperitoneum as shown in table (4).

Table 4: Mean airway pressure and $\mathrm{PaO} 2 / \mathrm{Fio} 2$ Ratio between both groups

\begin{tabular}{|l|l|l|l|}
\hline & Group V & Group P & P value \\
\hline $\begin{array}{l}\text { MAP Baseline (5 min } \\
\text { after intubation) }\end{array}$ & $7.3524 \pm 0.21682$ & $8.424 \pm 0.26918$ & $<0.001^{*}$ \\
\hline $\begin{array}{l}\text { MAP After } \\
\text { pneumoperitoneum }\end{array}$ & $7.3762 \pm 0.2781$ & $11.400 \pm 0.2781$ & $<0.001^{*}$ \\
\hline $\begin{array}{l}\mathrm{PaO}_{2} / \mathrm{Fio}_{2} \text { Ratio Baseline } \\
(5 \mathrm{~min} \text { after intubation) }\end{array}$ & $312.80 \pm 31.8053$ & $297.23 \pm 33.378$ & $<0.05^{*}$ \\
\hline $\begin{array}{l}\mathrm{PaO} / \text { Fio } 2 \text { Ratio after } \\
\text { pneumoperitoneum }\end{array}$ & $313.686 \pm 37.9766$ & $322.57 \pm 34.398$ & $>0.05$ \\
\hline
\end{tabular}

Values are presented as mean \pm SD.

* Statistically significant difference.

MAP mean airway pressure, $\mathrm{PaO}_{2} / \mathrm{FiO}_{2}$ partial oxygen tension to fractional inspiratory oxygen pressure.

\section{DISCUSSION}

Optimization of intraoperative mechanical ventilation can decrease the incidence of pulmonary postoperative complication and improve outcome especially in obese patients. As the classic ventilation mode, VCV has been used for many years to deliver a target tidal volume and thus ensure satisfactory minute ventilation, but its use frequently causes high pressure levels in obese patients ${ }^{(14)}$.

Although pressure-controlled (PC) ventilation potentially provides greater control over airway pressure by virtue of its decelerating inspiratory flow pattern, it remains a relatively less frequently used ventilation strategy in the operating theatre. Additionally, it ensures collapsed alveoli open up by extending inspiratory time using adequate positive end expiratory pressure levels ${ }^{(\mathbf{1 5})}$.

This study compared VCV and PCV during laparoscopic cholecystectomy in obese patients as regard hemodynamic changes (heart rate and mean arterial blood pressure), mean air way pressure, $\mathrm{PaO}_{2} / \mathrm{FiO}_{2}$ ratio, alveolar -arterial oxygen tension gradient, and dead space ventilation to tidal volume ratio showed that PCV does not adversely affect hemodynamics although it results in better oxygenation when compared to VCV.

Pressure-controlled ventilation was thought to adversely affect hemodynamics as it causes increase in mean airway pressure which results in decreased venous return and cardiac output ${ }^{(\mathbf{1 6})}$.

In the current study, it was found that there was no statistically significant difference in hemodynamics regarding heart rate and mean arterial blood pressure between the two groups.
Balick-Weber et al. (17) evaluated the hemodynamic consequences of laparoscopic urological procedures using transesophageal echocardiography for systolic as well as diastolic function. The authors noted PCV and VCV to be associated with statistically similar haemodynamic consequences, despite a significant, although small change in mean airway pressure with PCV compared with VCV.

A similar lack of effect on hemodynamic parameters was observed by Sen $\boldsymbol{e t}$ al. ${ }^{(5)}$ when they compared PCV and VCV ventilation in laparoscopic cholecystectomy.

Our study also demonstrated that, during laparoscopy, PCV had decreased peak airway pressure slightly but statistically significant when compared with VCV ventilation. This can be explained by the decelerating inspiratory flow pattern, also known as descending ramp, with the maximum value reached early in inspiration, then followed by a deceleration of the flow rate, resulting in its characteristic form. The peak pressure is limited thus, reducing the risk of barotraumas.

In similar studies; Tyagi et al. ${ }^{(11)}$ have observed lower peak airway pressure values without any changes in $\mathrm{PaO}_{2}$ values. Gupta et al. (14) also reported lower peak airway pressure levels with higher $\mathrm{PaO}_{2}$ in the PCV mode.

In the Balick-Weber et al. ${ }^{(17)}$ study; shift from the VCV to the PCV mode resulted in a fall in the peak airway pressure values and an increase in the compliance without any significant differences in oxygenation, systolic and diastolic heart functions.

Ogurlu et al. ${ }^{(18)}$ reported similar findings during laparoscopic gynecological operations. 
In contrast to results of this study, De Baerdemaeker et al. (19) found no statistical difference in peak airway pressure at $15 \mathrm{~min}$ after pneumoperitoneum in VCV group compared to PCV group in morbid obese patients undergoing laparoscopic gastric banding, this can be due to the use of constant minute ventilation in both groups.

Cadi et al. ${ }^{(10)}$, recorded high $\mathrm{PaO}_{2}$ levels and without significant alterations in the peak airway pressure, plateau pressure and mean airway pressure values in the patients ventilated with PCV mode.

As regard mean airway pressure, the present study showed significant increase in mean airway pressure in PCV group compared to VCV group.

Similar to the results of this study, Tyagi $\boldsymbol{e t}$ al. (11) in their study over 42 patients undergoing laparoscopic cholecystectomy found statistically significant increase in mean airway pressure at 10 and 30 min after pneumoperitoneum in PCV group compared to VCV group.

Along with the results of this study, BalickWeber and colleagues in 2007 found slight but significant increase in mean airway pressure in $\mathrm{PCV}$ group compared to VCV group during laparoscopic urological surgeries ${ }^{(17)}$.

The higher mean airway pressure seen in PCV is mostly a result of lengthening the inspiratory time (which is the time over which the tidal volume is delivered or the pressure is maintained depending on the mode of ventilation), this improves oxygenation as it allows redistribution of gas from more compliant alveoli to less compliant alveoli. Our study demonstrated that PCV significantly improves $\mathrm{PaO}_{2} / \mathrm{FiO}_{2}$ during laparoscopic cholecystectomy in obese patients.

However, higher oxygenation has been observed in some studies despite lack of significant differences in the airway pressure values. The improved oxygenation in the PCV mode may be attributed to ventilation with a higher flow rate and square wave pressure. The elevated flow at the beginning of inspiration causes faster rise in the pressure compared to the VCV mode and the earlier supply of a higher proportion of the tidal volume.

The fast alveoli with a short time constant may be overinflated at the start of the inspiration, but the subsequent homogenization of the tidal volume spread in the alveoli prevents the incidence of the development of atelectasis and improves ventilation perfusion matching. Also, despite the lowering of the inspiratory flow rate during the plateau pressure phase, the flow never reaches zero as in the VCV.

Along with these results, Cadi et al. ${ }^{(10)}$ in their study over 36 morbid obese patients undergoing laparoscopic gastric banding found significantly higher $\mathrm{PO}_{2} /$ fio2 in $\mathrm{PCV}$ than in VCV group.

In contrast to these results, Balick-Weber $\boldsymbol{e t}$ al. (17) noted no significant difference in arterial oxygenation in patients receiving PCV compared with the patients receiving VCV. This can be due to short time procedure where the recruitment of atelectic alveoli and also perfusion of collapsed alveoli may take some more time.

In our study, the patients receiving PCV showed a significantly lower value of alveolar-arterial oxygen tension gradient $\left(\mathrm{PAO}_{2}-\mathrm{PaO}_{2}\right)$ and dead space ventilation to tidal volume ratio compared with the patients receiving VCV. This can be explained by the decelerating inspiratory flow profile in PCV that enhances a more homogeneous distribution of the VT in all the ventilated alveoli follows, reducing the amount of atelectasis by improved alveolar recruitment. This mechanical effect of PCV allows better ventilation-perfusion matching which mean better oxygenation. Moreover, in VCV, higher intrathoracic pressure decreases the venous inflow into the thorax, leading to a fall in preload and the compression of pulmonary blood vessels raises pulmonary vascular resistance, which can impede right ventricular stroke output. Fall in right ventricular stroke output causes ventilation-perfusion mismatch in the lung, resulting in hypoxemia.

Cadi et al. ${ }^{(\mathbf{1 0})}$ also reported that, despite similar values for $\mathrm{PAO}_{2}-\mathrm{PaO}_{2}$ was significantly higher and $\mathrm{PaO}_{2} / \mathrm{FIO}_{2}$ was lower in the VCV group when compared with those in the PCV group during laparoscopic obesity surgery.

But in the cross over study done by BalickWeber et al. (17), they found no significant difference in the estimated $\mathrm{Vd} / \mathrm{Vt}$ ratio between the PCV and VCV during abdominal laparoscopy.

The major limitation of our study is our groups were healthy subjects. The findings of our study may not be clinically significant, but discrepancy in clinical consequences can be expected in patients with poor pulmonary function.

In addition, using PCV routinely requires a good knowledge of its operating principles and a careful setting of the alarm limits, particularly the MV and the Vt alarms; a sudden change in the patient's compliance could increase or lower those two variables.

PCV-VG is a novel mode of ventilation that has been utilized in recent years. PCV-VG is best described as a dual-control mode that ventilates with time-cycled pressure-limited ventilation but allows pressure to be adjusted to deliver a TV in a clinicianchosen range. 


\section{CONCLUSION}

As conclusion, in the current study, it was found that PCV is a better choice than VCV in obese patients undergoing laparoscopic cholecystectomy, because PCV improves arterial oxygenation when compared to VCV and also it results in lower peak airway pressure due to its characteristic decelerating flow pattern which decreases the risk of barotrauma. Also it was found that PCV does not adversely affect hemodynamics although it results in higher mean airway pressure when compared to VCV.

\section{REFERENCES}

1. Parameswaran K, Todd D and Soth M (2006): Altered respiratory physiology in obesity. Can Respir J., 13: 203210.

2. Haslam DW and James PT (2005): Obesity. The Lancet Journal, 366: 1197-209.

3. Oberg B and Poulson TD (1996): Obesity: an anesthetic challenge. Acta Anesthesiol Scand., 40: 191-200,

4. Gregory A, Audrey A, Abdourahamane $\mathbf{K}$ et al. (2008): Pressure-controlled Ventilation Does Not Improve Gas Exchange in Morbidly Obese Patients Undergoing Abdominal Surgery. Obes Surg., 18: 71-76.

5. Sen O, Umutoglu T, Aydin N et al. (2016): Effects of pressure-controlled and volume-controlled ventilation on respiratory mechanics and systemic stress response during laparoscopic cholecystectomy. Springer plus., 5:298-304.

6. Tantawy H (2018): Stoelting"s Anesthesia and CoExisting Disease. [ed.] Roberta L Hines and Katherine E Marschall. 7th edition. Philadelphia : ELSEVIER. pp. 297-309.

7. Koh SO (2007): Mode of mechanical ventilation: volume controlled mode. Crit Care Clin., 23(2):161-7.

8. Kheterpal S, Han R, Tremper KK et al. (2006): Incidence and predictors of difficult and impossible mask ventilation. Anesthesiology, 105(5):885-91.

9. Movassagi R, Montazer M, Mahmoodpoor A et al. (2017): Comparison of pressure vs. volume controlled ventilation on oxygenation parameters of obese patients undergoing laparoscopic cholecystectomy. Pak J Med Sci., 33(5):1117-1122.

10. Cadi P, Guenoun T, Journois D et al. (2008): Pressurecontrolled ventilation improves oxygenation during laparoscopic obesity surgery compared with volumecontrolled ventilation. Br J Anaesth., 100(5):709-16.

11. Tyagi A, Kumar R, Sethi AK et al. (2011): A comparison of pressure-controlled and volumecontrolled ventilation for laparoscopic cholecystectomy. Anaesthesia, 66(6):503-8.

12. Sinha CA and Eckmnn MD (2010): Anaesthesia for Bariatric Surgery. [ed.] Ahm Rah Miller, Iman Lam Eriksson and Ammar Lam Fleisher . Miller's Anesthesia. 7th edition. Churchill Livingstone : Elsevier.

13. Nightingale CE, Margarson MP, Shearer E et al. (2015): Peri-operative management of the obese surgical patient 2015: Association of Anaesthetists of Great Britain and Ireland Society for Obesity and Bariatric Anaesthesia., 70(7):859-76.

14. Gupta SD, Kundu SB, Ghose T et al. (2012): A comparison between volume-controlled ventilation and pressure-controlled ventilation in providing better oxygenation in obese patients undergoing laparoscopic cholecystectomy. Indian J Anaesth., 56(3):276-82.

15. Meininger D, Byhahn C, Mierdl S et al. (2005): Positive end-expiratory pressure improves arterial oxygenation during prolonged pneumoperitoneum. Acta Anaesthesiol Scand., 49(6):778-83.

16. Irwin MG, Ng JK (2001): Transoesophageal acoustic quantification for evaluation of cardiac function during laparoscopic surgery. Anaesthesia, 56(7):623-9.

17. Balick-Weber CC, Nicolas P, Hedreville-Montout $M$ et al. (2007): Ste'phan1 British Journal of Anaesthesia, 99 (3): 429-35.

18. Ogurlu M, Kucuk M, Bilgin F et al. (2010): Pressurecontrolled vs volume-controlled ventilation during laparoscopic gynecologic surgery. J Minim Invasive Gynecol., 17: 295-300.

19. De Baerdemaeker LE, Van der Herten C, Gillardin JM et al. (2008): Comparison of Volume-controlled and Pressure-controlled Ventilation during Laparoscopic Gastric Banding in Morbidly Obese Patients. Obes Surg., 18: 680-5. 